\title{
DESEMPENHO AGRONÔMICO DE RÚCULA ADUBADA COM VINHAÇA EM DIFERENTES SISTEMAS DE CULTIVO
}

\author{
Maristela Caetano Gomes ${ }^{1 *}$, Manoel Emiliano Lopes de Souza ${ }^{2}$, Adriana Ursulino Alves ${ }^{3}$, \\ Edivania de Araújo Lima ${ }^{4}$, Elaine Heberle ${ }^{5}$, Edson de Almeida Cardoso ${ }^{6}$
}

\author{
${ }^{1}$ Mestre em Ciências Agrárias, Universidade Federal do Piauí (UFPI), Bom Jesus - PI. Assentamento Palmares I, \\ Crateús-CE. *E-mail do autor correspondente: maristela_caetano@hotmail.com. \\ ${ }^{2}$ Mestre em Ciências Agrárias, Universidade Federal do Piauí (UFPI), Bom Jesus - PI. \\ ${ }^{3}$ Docente, Horticultura, Universidade Federal do Piauí (UFPI), Bom Jesus - PI. \\ ${ }^{4}$ Docente, Meteorologia, Universidade Federal do Piauí (UFPI), Bom Jesus - PI. \\ ${ }^{5}$ Doutora, Fitotecnia, Universidade Federal de Viçosa, Viçosa - MG. \\ ${ }^{6}$ Doutor, Fruticultura, Universidade Federal da Paraíba, Areia - PB.
}

Recebido: 22/02/2020; Aceito: 11/01/2021

RESUMO: A rúcula (Eruca sativa Mill.) é uma hortaliça de clima ameno e exigente em nutrientes. Sistemas de cultivo, como o uso de coberturas de solo e consorciamento de culturas, podem ser alternativas para o estabelecimento de um microclima mais adequado, com diminuição da temperatura e maior retenção da umidade do solo. Fontes alternativas de nutrientes, como a vinhaça, mostram-se promissoras na produção de hortaliças. Diante disso, objetivou-se avaliar os efeitos de sistemas de cultivo e adubação com vinhaça no cultivo de rúcula. O experimento foi realizado de fevereiro a março de 2018, em Bom Jesus-PI (09 04' $28^{\prime}$ 'S, 44 $21^{\prime}$ ' $31^{\prime \prime} \mathrm{W}$ e $277 \mathrm{~m}$ ). O delineamento empregado foi de blocos casualizados em esquema de parcelas subdivididas 6x3 (sistemas de cultivo x doses de adubação com vinhaça), com cinco repetições. Nas parcelas foram alocados os sistemas de cultivo: controlerúcula em cultivo solteiro e sem cobertura morta (CS); consórcio de rúcula + coentro (RC); consórcio de rúcula + hortelã-pimenta $(\mathrm{RH})$; rúcula + cobertura morta de maravalha $(\mathrm{RM})$; rúcula + cobertura morta de casca de arroz (RA); rúcula + cobertura com tecido-não-tecidoTNT (RT); e nas subparcelas as doses de adubação com vinhaça $\left(0 ; 30\right.$ e $\left.40 \mathrm{~m}^{3} \mathrm{ha}^{-1}\right)$. Foram avaliados os índices de clorofila a e b, número de folhas totais e comerciais, fitomassas fresca e seca e área foliar. Não houve efeito da associação entre sistemas de cultivo e adubação com vinhaça sobre o desempenho das plantas de rúcula. Entre os sistemas de cultivo, o consórcio com coentro apresentou maior média para o número de folhas, e junto com a casca de arroz, maiores médias de folhas comerciais. A casca de arroz promoveu maior massa fresca total e área foliar. Entre as doses de vinhaça, a dose $40 \mathrm{~m}^{3} \mathrm{ha}^{-1}$ promoveu maiores médias para número de folhas totais e comerciais, bem como de fitomassa fresca e seca e área foliar. $\mathrm{O}$ consórcio de rúcula com coentro e o uso da casca de arroz como cobertura morta de solo melhoram o desempenho agronômico da cultura, promovendo aumento do número de folhas totais e comerciais, fitomassa fresca e área foliar da rúcula 'Cultivada'. A adubação com uso de vinhaça é eficiente para a cultura da rúcula, aumentando o número de folhas totais, altura, fitomassa fresca e fitomassa seca e de área foliar da rúcula 'Cultivada'.

Palavras-chave: Eruca sativa Mill. Consórcio. Cobertura morta. Biofertilizante. Vinhoto. 


\title{
AGRONOMIC PERFORMANCE OF RÚCULA ADUBADA WITH VINASSE IN DIFFERENT CROP SYSTEMS
}

\begin{abstract}
Arugula (Eruca sativa Mill.) Is a vegetable of climate mild and nutrient demanding. Cultivation systems, such as the use of soil cover and intercropping, may be alternatives for the establishment of a microclimate with lower temperatures and higher retention of soil moisture. Alternative sources of nutrients, such as vinasse, are promising in the production of vegetables. The objective of this study was to evaluate the effects of vinasse cultivation and fertilization systems on arugula cultivation. The experiment was carried out from February to March 2018, in Bom Jesus-PI (09 04 '28"S, 44 21 '31"W and $277 \mathrm{~m})$. The experimental design was a randomized complete block design with $6 \times 3$ subdivision plots (cultivation systems $\mathrm{x}$ doses of vinasse fertilization), with five replications. In the plots were allocated the cropping systems: control-arugula in single crop and without cover dead (CS); consortium of arugula + coriander $(\mathrm{RC})$; consortium of arugula + peppermint $(\mathrm{RH})$; arugula + mulch blanket $(\mathrm{RM})$; arugula + mulch of rice hulls $(\mathrm{RA})$; arugula + blanket with non-wovenTNT (RT); and in the subplots the doses of manure with vinasse (0, 30 and $40 \mathrm{~m} 3 \mathrm{ha}-1)$. The values of chlorophyll a and $b$, number of total and commercial leaves, fresh and dry phytomasses and leaf area were evaluated. There was no effect of the association between cultivation systems and vinasse fertilization on the performance of arugula plants. Among the cultivation systems, the coriander consortium had a higher mean number of leaves and, together with the rice husk, higher average commercial leaves. Rice bark promoted greater total fresh mass and leaf area. Among the doses of vinasse, the dose $40 \mathrm{~m} 3 \mathrm{ha}-1$, promoted higher averages for number of total and commercial leaves, as well as of fresh and dry phytomass and leaf area. The arugula consortium with coriander and the use of the husk of rice as mulch soil improves the agronomic performance of the crop, promoting an increase in the number of total and commercial leaves, fresh phytomass and leaf area of the 'Cultivated' arugula. Fertilization using vinasse is efficient for arugula cultivation, increasing the number of total and commercial leaves, fresh phytomasses, and dry phytomass and leaf area of 'Cultivated' arugula.
\end{abstract}

Key words: Eruca sativa Mill. Intercropping. Mulch. Biofertilizer. Vinhoto.

\section{INTRODUÇÃO}

Pertencente à família das brássicas, a rúcula (Eruca sativa Mill.) é uma olerícola oriunda do mediterrâneo, cultivada no Brasil e em muitas regiões do mundo, para fins alimentícios e medicinais, rica em nutrientes como potássio e ferro e vitaminas A e C (SILVA, 2010; AZARENKO et al., 2012; PORTO et al., 2013).

Para boa produção, a cultura necessita temperatura com faixa ideal entre 15 e $18{ }^{\circ} \mathrm{C}$ (FIGUEIREDO et al., 2012). Temperaturas mais elevadas induzem o florescimento e enrijecimento das folhas, tornando a planta imprópria para o comércio e consumo (SANTOS, 2010a), além de favorecer a perda de umidade do solo, levando à perda da turgescência da planta, podendo causar sua morte (TAIZ et al., 2017). 
No entanto, devido aos avanços genéticos do melhoramento de plantas, atualmente o potencial de cultivo de rúcula em regiões com temperaturas mais elevadas é alto, desde que atendidas as suas exigências, principalmente as hídricas e nutricionais (GUSMÃO et al., 2003; FILGUEIRA, 2008), além da adoção de técnicas de manejo que visam melhorar o microambiente de cultivo.

Diversas pesquisas têm sido desenvolvidas com o intuito de minimizar o efeito causado pelo excesso de radiação solar, diminuir as temperaturas do solo, da planta e do microambiente que os circundam. Exemplo disso são os trabalhos com utilização de coberturas vegetais mortas (SOLINO et al., 2010) e sintéticas, como o tecido-não-tecido de polipropileno-TNT (SÁ; REGHIN, 2008), e o uso de consórcios de culturas (ALMEIDA et $a l .$, 2015), muitas vezes associados com o manejo da adubação.

Solino et al. (2010) e Almeida et al. (2015) observaram que o consórcio de rúcula com outras espécies, a cobertura do solo e a adubação não convencional contribuem para o melhor aproveitamento dos recursos ambientais. Outro efeito benéfico das coberturas é a maior proteção do solo e, consequentemente, a melhoria do desempenho agronômico das culturas (MONTEIRO NETO et al., 2014).

Devido à alta demanda da cultura por nutrientes e o alto custo dos adubos convencionais, pesquisas que visam estudar o potencial e efeito de fontes alternativas de nutrientes são cada vez mais importantes. Destacam-se os resíduos orgânicos industriais que normalmente seriam descartados, como a vinhaça, flor-de-seda, torta de mamona e manipueira; potenciais adubos orgânicos comumente chamados de biofertilizantes (SILVA, 2010; BASSO et al., 2013; ALMEIDA et al., 2015; MELLO et al., 2018).

A vinhaça é um resíduo líquido orgânico, rico em nutrientes, principalmente potássio, e o principal subprotudo da indústria sucroalcooleira, sendo resultante da produção de álcool ou bioetanol, a partir da cana-de-açúcar (MARQUES; PINTO, 2013). Estima-se que são gerados entre 9 e 14 litros de vinhaça por litro de álcool. No entanto, apenas uma pequena parte deste resíduo vem sendo retirada do ambiente, onde seria descartado, e reaproveitado na irrigação e na fertilização de culturas (BARROS et al., 2010; ESPAÑA-GAMBOA et al., 2012).

Em pesquisas realizadas com vinhaça em alface, Ueno et al. (2014) e Dalri et al. (2014) obtiveram incremento na produção de matéria da parte aérea e acúmulo de nutrientes elevando a produtividade e a eficiência de uso da adubação. Santos (2010b) desenvolveu uma solução nutritiva a base de vinhaça para cultivo hidropônico de rúcula que permitiu o crescimento satisfatório da cultura, sendo considerada um adubo barato, com custo cerca de $70 \%$ menor que a solução convencionalmente utilizada.

Estudos envolvendo sistemas de cultivo que amenizem os danos por condições ambientais desfavoráveis, como altas temperaturas e baixa umidade, associados a adubação com fontes alternativas, reutilizando resíduos da indústria, para hortaliças, são escassos. Diante disso, objetivou-se avaliar os efeitos de sistemas de cultivo e adubação com vinhaça no cultivo de rúcula. 


\section{MATERIAL E MÉTODOS}

\section{Caracterização da área experimental}

O experimento foi realizado em área experimental no Campus Professora Cinobelina

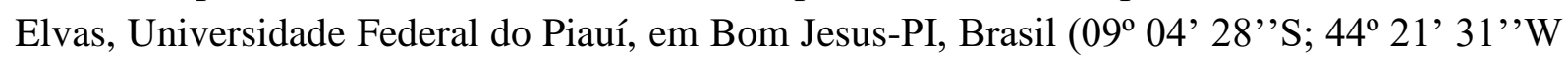
e $277 \mathrm{~m})$.

O clima da região é quente e úmido, classificado por Köppen como Awa (tropical chuvoso com estação seca no inverno e temperatura média do mês mais quente maior que 22 ${ }^{\circ} \mathrm{C}$ ), apresentando médias anuais de temperatura de $26,2{ }^{\circ} \mathrm{C}$ e precipitação entre 900 a 1200 mm (INMET, 2018).

O período experimental foi de Fevereiro a Março de 2018, sendo observadas médias de temperatura do ar $\left({ }^{\circ} \mathrm{C}\right)$ de $25,93{ }^{\circ} \mathrm{C}$, umidade relativa $78 \%$ e precipitação de $230 \mathrm{~mm}$ mês ${ }^{-1}$. Foram registrados valores de umidade relativa do ar mínima de $39 \%$ e temperaturas mínima e máxima de 21 e $34^{\circ} \mathrm{C}$, respectivamente (INMET, 2018).

\section{Delineamento experimental e Tratamentos}

O delineamento empregado foi de blocos casualizados em esquema de parcelas subdivididas $6 \mathrm{x} 3$ (sistemas de cultivo $\mathrm{x}$ doses de adubação com vinhaça), com cinco repetições.

Nas parcelas foram alocados os sistemas de cultivo: controle- rúcula em cultivo solteiro e sem cobertura morta (CS); consórcio de rúcula + coentro (RC); consórcio de rúcula + hortelã-pimenta $(\mathrm{RH})$; rúcula + cobertura morta de maravalha $(\mathrm{RM})$; rúcula + cobertura morta de casca de arroz (RA); rúcula + cobertura com tecido-não-tecido-TNT (RT) e nas subparcelas as doses de adubação com vinhaça (0; 30 e $\left.40 \mathrm{~m}^{3} \mathrm{ha}^{-1}\right)$ (Gariglio et al., 2014).

Utilizou-se rúcula 'Cultivada' (Eruca sativa Mill.) e, para o consórcio, coentro 'HTV Dom Luiz' (Coriandrum sativum L.) e hortelã-pimenta (Menta piperita L.). Para cobertura do solo utilizou-se maravalha de madeira de eucalipto, casca de arroz in natura (ambas adquiridas na região e sem qualquer tratamento ou utilização anterior ao experimento) e tecido-não-tecido de polipropileno- TNT branco. A vinhaça foi adquirida em uma microdestilaria da Cooperativa de Produtores de Cana-de-Açúcar de Palmeira do Piauí, localizada no distrito de Palmeira do Piauí, sendo os resultados da análise química apresentados na Tabela 1.

Tabela 1. Resultado da análise química da vinhaça utilizada no cultivo de rúcula. Result of chemical analysis of vinasse used in arugula cultivation.

\begin{tabular}{ccccccc}
\hline $\mathrm{N}$ & $\mathrm{P}$ & $\mathrm{K}$ & $\mathrm{S}$ & $\mathrm{Ca}$ & $\mathrm{Mg}$ & $\mathrm{Na}$ \\
& - & - & \\
\hline 196,00 & 275,54 & 879,76 & 905,00 & 352,50 & 122,80 & 25,00 \\
\hline
\end{tabular}

Nota: N: nitrogênio; P: fósforo; K: potássio; S: enxofre; Ca: cálcio; Mg: magnésio; Na: Sódio. N: nitrogen; P: phosphorus; K: potassium; S: sulfur; Ca: calcium; Mg: magnesium; Na: Sodium

Fonte: Autoria própria. Own authorship. 


\section{Condução do experimento}

O solo, um Latossolo Amarelo distrófico (EMBRAPA, 2013), foi previamente preparado com calagem de acordo com as recomendações, objetivando alcançar a saturação por bases de 80\%, conforme recomendação de Trani et al. (1997).

Posteriormente, realizou-se adubação de base com composto orgânico (esterco de caprino + folhas de eucalipto), sendo incorporados $10 \mathrm{~L} \mathrm{~m}^{-2}$ de canteiro (SILVA et al., 2018) na camada de $0-20 \mathrm{~cm}$. Após pousio de 7 dias foi realizada a coleta do solo para análise físico-química (Tabela 2), observando-se que o mesmo apresentava $\mathrm{pH}$ e fertilidade adequados para o cultivo da rúcula (TRANI, 1992). Em seguida foram realizadas, mecanicamente, gradagem e confecção dos canteiros.

Tabela 2. Resultado da análise físico-química do solo $(0-20 \mathrm{~cm})$ da área de cultivo de rúcula. Result of the physical-chemical analysis of the soil $(0-20 \mathrm{~cm})$ of the arugula cultivation area.

\begin{tabular}{|c|c|c|c|c|c|c|c|c|c|c|c|}
\hline \multirow[t]{2}{*}{$\mathrm{pH}$} & $\mathrm{P}$ & $\mathrm{K}$ & $S$ & $\mathrm{Ca}$ & $\mathrm{Mg}$ & $\mathrm{Al}$ & $\mathrm{H}+\mathrm{A}$ & SB & $\mathrm{T}$ & \multirow{2}{*}{$\begin{array}{c}\mathrm{V} \\
(\%)\end{array}$} & \multirow{2}{*}{$\begin{array}{c}\mathrm{MO} \\
\left(\mathrm{g} \mathrm{kg}^{-1}\right)\end{array}$} \\
\hline & ---- & $\mathrm{g} \mathrm{dm}^{-3}$ & -- & & & $(\mathrm{cm}$ & $\mathrm{C} \mathrm{dm}$ & & & & \\
\hline 5,9 & 174,4 & 114,0 & 2,5 & 3,62 & 1,65 & 0,0 & 1,3 & 5,56 & 6,86 & 81 & 37,7 \\
\hline
\end{tabular}

Nota: $\mathrm{pH}$ em $\mathrm{H}_{2} \mathrm{O}$; P: fósforo; $\mathrm{K}$ : potássio; $\mathrm{S}$ : enxofre; Ca: cálcio; Mg: magnésio; Al: alumínio; $\mathrm{H}+\mathrm{Al}$ : acidez potencial; SB: soma de bases; T: capacidade troca de cátions; V: Saturação por bases; MO: matéria orgânica. Note: $p \mathrm{H}$ in $\mathrm{H}_{2} \mathrm{O}$; P: phosphorus; $\mathrm{K}$ : potassium; $\mathrm{S}$ : sulfur; Ca: calcium; Mg: magnesium; Al: aluminum; $\mathrm{H}+$ Al: potential acidity; SB: sum of bases; T: cation exchange capacity; V: Base saturation; MO: organic matter Fonte: Autoria própria. Own authorship.

A parcela teve dimensões de $2 \mathrm{~m}^{2}$ e as subparcelas $0,2 \mathrm{~m}^{2}$. O espaçamento utilizado para semeadura foi de 0,10 x $0,20 \mathrm{~m}$, com dez linhas por parcela, e duas linhas por subparcela, separadas entre si por duas linhas não adubadas com vinhaça.

A semeadura da rúcula foi manual, diretamente no campo, depositando-se de quatro a cinco sementes por covas de $0,05 \mathrm{~m}$ de profundidade. O desbaste aconteceu 14 dias após a semeadura (DAS), deixando-se apenas uma planta por cova, com densidade de plantio de 500.000 plantas ha $^{-1}$.

As regas foram diárias e feitas duas vezes ao dia, através de microaspersão com mangueira microperfurada para irrigação, e de acordo com a necessidade da cultura,

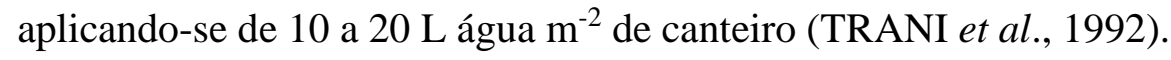

Para evitar possível competição durante o período inicial de crescimento da rúcula, o coentro foi semeado após sua emergência, semeando-se cerca de $4 \mathrm{~g}$ de sementes por metro linear, a partir daí, convivendo em consórcio até o fim do ciclo da cultura principal. Foram feitas mudas de hortelã-pimenta dois meses antes da semeadura da rúcula, sendo posteriormente transplantadas para o campo com espaçamento de 0,10 x 0,20 m. As linhas de consórcios ficaram espaçadas $0,10 \mathrm{~m}$ da cultura principal.

O transplante das mudas de hortelã-pimenta, disposição das coberturas e a adubação com vinhaça nas parcelas foram feitas 15 DAS. As coberturas com casca de arroz e maravalha foram colocadas manualmente, espalhando-se uma camada uniforme com espessura de aproximadamente $2,0 \mathrm{~cm}$, tomando-se o cuidado para não encobrir nenhuma planta. $\mathrm{O}$ TNT foi cortado em faixas com as mesmas dimensões da parcela, estendido e esticado sobre a 
mesma, sendo fixado por estacas rentes ao solo. Após, foram abertos furos no tecido, em cada cova, para exposição das plantas. As doses de vinhaça foram diluídas em 1 litro de água e aplicadas uniformemente sobre as subparcelas com uso de regador manual.

\section{Amostragem e coleta de dados}

A coleta das plantas para as análises aconteceu 35 DAS (LINHARES et al., 2009) obtendo-se, para fins de avaliação, três amostras por subparcela, cada amostra representada por uma planta escolhida aleatoriamente (totalizando nove plantas por parcela). Após colheita manual das plantas inteiras, estas foram lavadas em água corrente para retirada de materiais aderidos e, posteriormente, lavadas com água destilada e transportadas em sacos plásticos até o laboratório para avaliação das seguintes variáveis:

Índices de clorofila a e b: foram medidos indiretamente pelo índice de clorofila Falker- ICF, aferidos com equipamento clorofilômetro (clorofiLOG-CFL1030). As leituras foram realizadas antes da colheita, utilizando-se de uma folha escolhida aleatoriamente do terço médio da roseta.

Número de folhas: a parte aérea foi separada das raízes com auxílio de lâmina cortante e as folhas separadas do colo, sendo contadas uma a uma, considerando-se todas as folhas totalmente expandidas.

Altura: Para altura foi utilizada régua graduada. Onde a altura foi medida com base na folha mais alta de cada planta, medindo-se a partir de $0,05 \mathrm{~m}$ em relação ao solo até a extremidade da mesma.

Fitomassa fresca total: obtida com uso de balança analítica de precisão pesando-se toda a planta, constituída de folhas, raízes e colo.

Fitomassa seca total: após pesagem para obtenção da massa fresca e contagem do número de folhas, as plantas foram colocadas em sacos de papel e secas em estufa com circulação forçada de ar a $65{ }^{\circ} \mathrm{C}$ até atingir massa constante, depois pesadas em balança analítica de precisão.

Área foliar: para determinação utilizou-se o programa digital de processamento de fotografias ImageJ®. Todas as folhas foram separadas e colocadas em superfície plana e branca, para proporcionar o contraste necessário, utilizando-se uma placa de vidro por cima para ajustá-las de modo que ficassem inteiramente abertas no momento de fotografar.

As imagens foram feitas com câmera Nikon®/Coolpix P510, com resolução máxima de 14.2 MP, sem 'flash' e apoiadas a uma distância fixa de $0,5 \mathrm{~m}$ de distância. Na superfície onde foram colocadas as estruturas vegetais foi também colocada uma régua graduada, para que durante o processamento de dados pudesse ser feita a calibração, estabelecendo uma escala de conversão entre pixels e centímetros. Após coleta das imagens, as mesmas foram processadas no programa supracitado, onde foram obtidos os valores referidos de área foliar.

\section{Análise estatística}

Os dados foram submetidos à análise de variância pelo teste $\mathrm{F}$, a $5 \%$ de probabilidade, utilizando-se o software Sisvar (Ferreira, 2011). Identificada a diferença entre os tratamentos, aplicou-se o teste de Tukey as médias, ao nível de 5\% de significância. 


\section{RESULTADOS E DISCUSSÃO}

Não houve interação significativa entre sistemas de cultivo e doses de adubação com vinhaça $(\mathrm{p}<0,05)$, indicando que os fatores avaliados têm respostas independentes e, assim, são discutidos separadamente.

\section{Efeito dos Sistemas de Cultivo}

Para sistemas de cultivo foram observadas diferenças significativas entre tratamentos para o número de folhas totais, altura, fitomassa fresca e área foliar (Tabela 3), não havendo diferença para a fitomassa seca e índices de clorofila a e b, com médias de 5,77 g planta ${ }^{-1}$, 35,07 e 8,94, respectivamente.

As plantas cultivadas em consórcio com coentro $(\mathrm{RC})$ produziram maior número de folhas totais do que o controle e as cultivadas com cobertura de TNT (7,6 e 9,3\%, respectivamente). Os demais tratamentos foram intermediários, não se diferenciando do melhor tratamento nem da testemunha (Tabela 3 ).

Tabela 3. Valores médios do número de folhas totais (NFT), altura, fitomassa fresca (FF) e área foliar de plantas de rúcula em diferentes sistemas de cultivo. Average values of the number of total leaves (NFT), height, fresh phytomass $(F F)$ and leaf area of arugula plants in different cultivation systems.

\begin{tabular}{ccccc}
\hline $\begin{array}{c}\text { Sistemas de } \\
\text { cultivo }\end{array}$ & NFT & Altura(cm) & $\begin{array}{c}\text { FF } \\
\left(\mathbf{g ~ p l a n t a}^{-1}\right)\end{array}$ & $\begin{array}{c}\text { AF } \\
\left(\mathbf{c m}^{\mathbf{2}} \text { planta-1 }^{-1}\right)\end{array}$ \\
\hline CS & $11,72 \mathrm{~b}$ & $16,31 \mathrm{ab}$ & $33,84 \mathrm{ab}$ & $257,88 \mathrm{~b}$ \\
RC & $12,68 \mathrm{a}$ & $16,88 \mathrm{ab}$ & $35,75 \mathrm{a}$ & $265,39 \mathrm{~b}$ \\
RH & $11,93 \mathrm{ab}$ & $15,20 \mathrm{~b}$ & $34,43 \mathrm{ab}$ & $211,52 \mathrm{~b}$ \\
RM & $11,63 \mathrm{~b}$ & $16,44 \mathrm{ab}$ & $35,37 \mathrm{ab}$ & $224,26 \mathrm{~b}$ \\
RA & $12,41 \mathrm{ab}$ & $19,32 \mathrm{a}$ & $34,48 \mathrm{ab}$ & $334,38 \mathrm{a}$ \\
RT & $11,5 \mathrm{~b}$ & $15,88 \mathrm{ab}$ & $33,23 \mathrm{~b}$ & $262,78 \mathrm{~b}$ \\
\hline CV $(\%)$ & 6,76 & 18,50 & 5,54 & 23,0 \\
\hline
\end{tabular}

Nota: Médias seguidas de mesma letra, para uma mesma variável, não diferem entre si pelo teste de Tukey a 5\% de probabilidade. CS: Controle- rúcula em cultivo solteiro e sem cobertura morta; RC: Consórcio de rúcula + coentro; RH: Consórcio de rúcula + hortelã-pimenta; RM: Rúcula em cobertura morta de maravalha; RA: Rúcula em cobertura morta de casca de arroz; RT: Rúcula em mulching com tecido-não-tecido-TNT. Note: Averages followed by the same letter, for the same variable, do not differ by the Tukey test at 5\% probability. CS: Arugula control in single cultivation and without mulch; RC: Consortium of arugula + coriander; RH: Consortium of arugula + peppermint; RM: Arugula in shavings mulch; RA: Arugula in rice husk mulch; RT: Arugula in mulching with non-woven fabric-TNT.

Fonte: Autoria própria. Own authorship.

Resultados semelhantes aos deste trabalho foram encontrados por Oliveira et al. (2010) estudando o consórcio da rúcula com alface, onde encontraram média de 13,3 folhas por planta, e por Jesus et al. (2018), que estudaram o efeito da adubação silicatada e o déficit hídrico em plantas de rúcula e perceberam que o número de folhas variou entre 5,8 e 10 folhas por planta.

Para o comprimento foliar, representado pela altura $(\mathrm{cm})$ têm-se que o tratamento que obteve maior média foi o tratamento com casca de arroz (RA), com 19,32 cm, os demais 
tratamentos não se diferenciaram da testemunha, exceto RH no qual foi observado o menor crescimento das plantas, com média de $15,20 \mathrm{~cm}$ (Tabela 3).

Almeida et al. (2015) estudando a consorciação de rúcula com alface adubadas com flor-de-seda (Calotropis procera), obtiveram médias de altura de 28,44 e 15,16 cm.

A quantidade e altura de folhas podem variar conforme a genética, mas também de acordo com as mudanças no meio que a cerca (BRZEZINSKI et al., 2017). Fatores externos como temperatura do ar, umidade do solo e o suprimento de nutrientes afetam o crescimento e o desenvolvimento foliar (KERBAUY, 2009). Como o produto economicamente importante da rúcula são as folhas, o aumento de seu número e altura é benéfico para o produtor desta hortaliça.

Embasados nisto e nos resultados obtidos nesta pesquisa, o aumento de folhas naqueles tratamentos com cobertura de casca de arroz (RA) e em consórcio com o coentro (RC) pode ter acontecido devido a mudanças no ambiente. Mudanças essas como a diminuição das temperaturas de solo e do ar e manutenção da umidade, provocadas pela cobertura do solo ao redor das plantas de rúcula. Enquanto os outros tratamentos podem não ter fornecido tais benefícios para a cultura, portanto, apresentando menor folhagem.

Para área foliar, os resultados mais expressivos foram observados quando se utilizou a cobertura morta de casca de arroz (RA), apresentando $334,38 \mathrm{~cm}^{2}$ planta $^{-1}$ (Tabela 3).

Os incrementos proporcionados por $\mathrm{RC}$ e $\mathrm{RA}$, apresentando maior número médio de folhas, área foliar e fitomassa fresca, podem estar relacionados com o fato de que tanto o consórcio, pela maior densidade de plantas por área, como a cobertura de casca de arroz, promove a proteção do solo contra a radiação solar (FURLANI et al., 2008).

Com isso, diminuindo temperaturas que incidem sobre o solo e sobre a planta, como afirmam também Monteiro Neto et al. (2014) ao concluírem que a casca de arroz e a maravalha aumentam todas as características produtivas das cultivares de alface 'Grandes Lagos' e 'Verônica'.

Os resultados de massa fresca repetiram o comportamento das outras variáveis, onde os maiores valores foram proporcionados, entre os sistemas de cultivo, pelo consórcio com coentro (RC), com média de massa fresca de 35,75 $\mathrm{g}$ planta $^{-1}$ (Tabela 3).

O uso de cobertura morta em rúcula adubada com composto orgânico eleva a sua produtividade e a matéria fresca, como relatam Solino et al. (2010) ao cobrirem o solo com ervas espontâneas, observando média de 48,9 $\mathrm{g}_{\text {planta }}{ }^{-1}$. Como relatam os autores, a cobertura, viva ou morta promove também alterações físico-químicas no solo, além de reduzirem a incidência de plantas invasoras.

Costa et al. (2007) relatam que para a rúcula, o consórcio com alface em duas épocas de semeadura aumenta os teores de fitomassa fresca, concluindo que este método é eficaz no que diz respeito ao aumento da produção, o que para o presente estudo se mostra verdade, visto que a associação da cultura em consórcio e o uso de cobertura promoveram aumento do acúmulo de fitomassa em relação a outros sistemas de cultivo. Assim como observado por Sugasti (2012), ao testar o cultivo consorciado entre alface, quiabo e rabanete concluiu que o 
aumento no crescimento das plantas é proporcionado pela associação das culturas em consórcio, que leva à diminuição das variações de temperatura e umidade, quando comparadas com o cultivo solteiro.

Além disso, estas coberturas de solo podem ter diminuído a evaporação de água, o suficiente para aumentar a eficiência da irrigação, diminuindo a incidência solar direta e as forças de retenção do solo, que permanece úmido por mais tempo, aumentando a disponibilidade de água para as plantas e o aporte de nutrientes para seu pleno desenvolvimento (MARTORANO et al., 2009; FAGERIA; MOREIRA, 2011). Como comprovado por Resende et al. (2005), que ao utilizarem casca de arroz e maravalha como cobertura de solo no cultivo da cenoura (Daucus carota L.) concluíram que o uso de tais materiais como cobertura melhoram as características hidrotérmicas do solo e aumentam a produtividade da cultura.

A rúcula é uma hortaliça folhosa que pode possuir mais de $95 \%$ do seu peso total apenas de água (OLIVEIRA et al., 2015). A deficiência de água nos tecidos promove mudanças na estrutura celular, causando danos que podem ser irreversíveis (OLIVEIRA et al., 2011). Portanto o maior déficit hídrico, causado pela insolação intensa sobre o solo e os tecidos, pode ter sido capaz de alterar seu desenvolvimento, diminuindo o crescimento daquelas plantas em tratamentos sem cobertura ou com cobertura ineficiente, como no cultivo solteiro e sem cobertura, consórcio com hortelã (RH) e cobertura com maravalha (RM) e TNT (RT), já que a redução da área foliar ocorre logo após a submissão da planta a regimes de déficit de água (TAIZ; ZEIGER, 2013).

\section{Efeitos da Adubação com Vinhaça}

Entre as doses de vinhaça, foram verificadas diferenças para todas as características avaliadas, exceto índices de clorofila a e b, que obtiveram médias de 35,07 e 8,94, respectivamente.

Tabela 4. Valores médios do número de folhas total (NFT), número de folhas comerciais (NFC), fitomassa fresca (FF), fitomassa seca (FS) e área foliar de rúcula 'Cultivada' adubada com vinhaça. Average values of the total number of leaves (NFT), number of commercial leaves (NFC), fresh phytomass (FF), dry phytomass (FS) and arable leaf area 'Cultivated' fertilized with vinasse.

\begin{tabular}{cccccc}
\hline $\begin{array}{c}\text { DOSE } \\
\left(\mathbf{m}^{\mathbf{3}} \mathbf{h a} \mathbf{A}^{-1}\right)\end{array}$ & NFT & $\begin{array}{c}\text { Altura } \\
(\mathbf{c m})\end{array}$ & $\begin{array}{c}\text { FF } \\
\left(\mathbf{g ~ p l a n t a}^{-1}\right)\end{array}$ & $\begin{array}{c}\text { FS } \\
\left(\mathbf{g ~ p l a n t a}^{-1}\right)\end{array}$ & $\begin{array}{c}\text { AF } \\
\left(\mathbf{c m}^{\mathbf{2}} \mathbf{p l a n t a}^{-1}\right)\end{array}$ \\
\hline 0 & $11,36 \mathrm{~b}$ & $14,85 \mathrm{c}$ & $34,19 \mathrm{~b}$ & $4,97 \mathrm{c}$ & $204,92 \mathrm{c}$ \\
30 & $11,04 \mathrm{~b}$ & $16,28 \mathrm{~b}$ & $33,31 \mathrm{~b}$ & $5,53 \mathrm{~b}$ & $243,30 \mathrm{~b}$ \\
40 & $13,53 \mathrm{a}$ & $18,88 \mathrm{a}$ & $36,06 \mathrm{a}$ & $6,82 \mathrm{a}$ & $329,90 \mathrm{a}$ \\
\hline $\mathrm{CV}(\%)$ & 7,03 & 11,40 & 5,51 & 11,87 & 13,05
\end{tabular}

Nota: Médias seguidas de mesma letra, para uma mesma variável, não diferem entre si pelo teste de Tukey a $5 \%$ de probabilidade. Note: Averages followed by the same letter, for the same variable, do not differ by the Tukey test at $5 \%$ probability

Fonte: Autoria própria. Own authorship.

A dose que proporcionou maior média do número de folhas foi $40 \mathrm{~m}^{3} \mathrm{ha}^{-1}$, com média $16,03 \%$ maior de folhas totais e $16,64 \%$ de folhas comerciais em relação àquela que não 
sofreu adubação (Tabela 4). Esse acréscimo de folhas se traduz em maior lucro para o produtor, visto que a venda é o maço dessas folhas.

O aumento no aporte de nutrientes no solo, fornecidas pela adição de vinhaça contribui com o aumento do número de folhas no tratamento onde se aplicou a maior dose $\left(40 \mathrm{~m}^{3} \mathrm{ha}^{-1}\right)$ (DALRI et al., 2014). Ueno et al. (2013) utilizando vinhaça como fonte de nutrientes na fertirrigação de alface hidropônica, relatam que seu uso como biofertilizante também aumentou o número médio de folhas da cultura.

$\mathrm{Na}$ dose $40 \mathrm{~m}^{3} \mathrm{ha}^{-1}$ as plantas apresentaram altura maior que as demais, enquanto a dose $30 \mathrm{~m}^{3} \mathrm{ha}^{-1}$ foi superior à testemunha, com médias de 18,88 e 16,28 cm, respectivamente.

Caixeta et al. (2017), estudaram o efeito de fontes de adubação (cama de frango, esterco bovino + MAP e adubo mineral 4-14-4) em rúcula. Os tratamentos com uso de adubação orgânica obtiveram médias de altura inferiores aos deste experimento, com altura de 13,75 e $16,68 \mathrm{~cm}$, porém comprimento maior quando se utilizou adubo mineral $25,25 \mathrm{~cm}$ ).

Maior comprimento e número de folhas torna a planta mais capaz de realizar fotossíntese e produzir carboidratos, contribuindo para maior acúmulo de matéria seca ao longo do tempo, até que a área foliar ainda seja suficientemente eficiente (HELDT; PIECHULLA, 2011; TAIZ; ZEIGER, 2013). Para a rúcula, a área foliar tem uma relação direta com a produção e produtividade, visto que quanto maior a área de folhas, maior será a quantidade de produto e de lucro na comercialização. Pode-se observar que houve diferença para esta característica, sendo a dose $40 \mathrm{~m}^{3} \mathrm{ha}^{-1}$ aquela que proporcionou média de área foliar maior em relação as outras doses, $329,90 \mathrm{~cm}^{2}$ planta $^{-1}$ (Tabela 4).

Esta é uma variável fundamental em estudos como esse, pois através do dimensionamento e da funcionalidade do aparelho fotossintético, avalia-se a aptidão da planta em transformar energia através da fotossíntese, considerando que quanto maior a área foliar maior será essa capacidade de transformação, que culminará em índices desejáveis de produtividade (KERBAUY, 2009; PEIXOTO et al., 2011; FIRMINO et al., 2015; TAIZ et al., 2017).

Ao utilizarem fertilizantes alternativos para a rúcula, Silva et al. (2008) submeteram a cultura a níveis de salinidade e à adubação orgânica com esterco bovino, ovino/caprino e húmus de minhoca, tendo relatado médias de 115,6 a 308,7 $\mathrm{cm}^{2}$ planta $^{-1}$, sendo as maiores médias atribuídas ao tratamento com esterco bovino. Cavallaro Júnior et al. (2009), utilizando materiais orgânicos como farinha de chifres, cascos e ossos, e Pimentel et al. (2010) utilizando feijão-guandu (Cajanus cajan L.) como fertilizantes, concluem que devido a baixa relação $\mathrm{C}: \mathrm{N}$ desses materiais, assim como a vinhaça, há uma rápida mineralização de seus nutrientes, aumentando a capacidade de nutrição do solo para a rúcula.

A massa acumulada de uma planta reflete o produto do acúmulo de fotoassimilados produzidos pelo aparelho fotossintético e sua eficiência, no que diz respeito ao bom funcionamento deste aparelho, quando submetido as condições nutricionais e edafoclimáticas adequadas aos ecossistemas agrícolas (KERBAUY, 2009; TAIZ; ZEIGER, 2013). 
Os resultados de massa fresca (Tabela 4) repetiram o comportamento das outras variáveis, onde os maiores valores foram proporcionados pelo uso de $40 \mathrm{~m}^{3} \mathrm{ha}^{-1}$ de vinhaça que propiciou $36,06 \mathrm{~g} \mathrm{planta}^{-1}$.

Observa-se também que houve diferença para as médias de fitomassa seca nas doses de adubação, onde a dose de $40 \mathrm{~m}^{3} \mathrm{ha}^{-1}$ proporcionou cerca de 27 e $18 \%$ a mais, em relação à testemunha e à dose intermediária, respectivamente.

Na cultura da alface (Lactuca sativa L.) o uso da vinhaça como biofertilizante aplicado ao solo, promoveu aumento dos nutrientes nos tecidos e da fitomassa seca (UENO et al., 2013).

Para Souza et al. (2016) o uso de biofertilizante de origem vegetal, a base de Calotropis procera, no cultivo de rúcula promove maior rendimento de massa seca e verde, com valores médios de 2,44 e $45 \mathrm{~g}$, respectivamente. Estes estudos, corroboram com o fato de que o uso de biofertilizante a base de vinhaça promoveu incrementos no acúmulo de fitomassa de rúcula.

Este resíduo é utilizado em estudos como biofertilizante, tanto para hortaliças como para outros tipos de cultura, sendo empregado para incrementar e manter a fertilidade nos sistemas de cultivo, por ser rico em nutrientes, principalmente em potássio, mas também em cálcio, magnésio e enxofre (NEGRINI, 2007; BASSO et al., 2013; OLIVEIRA et al., 2014). Essa capacidade de agir como biofertilizante, disponibilizando nutrientes para consumo pelas plantas pode ter acarretado no aumento do desempenho agronômico à medida em que se utiliza $40 \mathrm{~m}^{3} \mathrm{ha}^{-1}$ no cultivo de rúcula.

Apesar de serem escassos os estudos que abordem este tema para a cultura da rúcula, resultados na literatura corroboram com os deste estudo, como os de Dalri et al. (2014) que avaliaram o desenvolvimento de alface submetida à fertirrigação com doses de vinhaça concentrada e concluíram que há eficácia na aplicação deste biofertilizante, aumentando a produtividade da cultura em relação à adubação potássica convencional.

Santos (2010) não encontrou diferença no comprimento e no número de folhas de rúcula em relação à utilização da solução convencional no sistema hidropônico. Por outro lado, em condições de campo, o manjericão (Ocimum basilicum L.) responde positivamente a aplicações de doses de vinhaça, aumentando os valores das características biométricas, porém não interferindo na produtividade da cultura (PALARETTI et al., 2015). E para o tomate, a prática da adubação com vinhaça traz benefícios como o aumento da produtividade, trazendo ganhos tanto no crescimento como no rendimento da cultura (GOLCHIN et al., 2017).

Dada a sua baixa relação $\mathrm{C}: \mathrm{N}$, a vinhaça possibilita uma rápida disponibilidade de nutrientes prontamente disponíveis para serem absorvidos pela planta na solução do solo (TEIXEIRA et al., 2009), isso é importante, considerando o ciclo curto que uma hortaliça como a rúcula possui (SANTOS, 2010).

Outro fator importante é que, sendo a rúcula uma cultura rica no elemento potássio (PORTO et al., 2013), significa dizer que a mesma também demanda quantidades elevadas desse nutriente, cabendo à vinhaça suprir essa demanda e, mais do que isso, atuar no aumento da quantidade de folhas e de fitomassa em relação à não utilização desse biofertilizante. 
Por outro lado, se o suprimento deste nutriente for inadequado, haverá prejuízos em diversas áreas onde tem funcionalidade, como na regulação osmótica (MARENCO; LOPES, 2009), ativação enzimática, alongamento celular e transporte de açúcares pelo floema, bem como a diminuição da quantidade de matéria fresca acumulada (KERBAUY, 2009; TAIZ; ZEIGER, 2013). Os referidos autores relatam que tais prejuízos acontecem devido a alterações no metabolismo causadas principalmente ao aparelho fotossintético.

\section{CONCLUSÕES}

Não há efeito da associação entre sistemas de cultivo e adubação com vinhaça para a rúcula 'Cultivada'

O consórcio de rúcula com coentro e o uso da casca de arroz como cobertura morta de solo aumentam o número de folhas, fitomassa fresca, altura e área foliar de plantas de rúcula.

A adubação com $40 \mathrm{~m}^{3}$ de vinhaça ha-1 é eficiente para a cultura da rúcula, promovendo aumento do número de folhas, fitomassas fresca e seca, altura e de área foliar de rúcula 'Cultivada'.

\section{REFERÊNCIAS BIBLIOGRÁFICAS}

ALMEIDA, A. E. S.; BEZERRA NETO, F.; COSTA, L. R.; SILVA, M. L.; LIMA, J. S. S.; BARROS JÚNIOR, A. P. Eficiência agronômica do consórcio alface-rúcula fertilizado com flor-de-seda. Revista Caatinga, Mossoró, v. 28, n. 3, p.79-85, 2015.

AZARENKO, O.; JORDAN, M. A.; LESLIE, W. Erucin, the major isothiocyanate in arugula (Eruca sativa), inhibits proliferation of MCF7 tumor cells by suppressing microtubule dynamics. National Library of Medicine National Institutes of Health, [s. l.], v. 9, n. 6, p.79-85, 2014.

BARROS, R. P.; VIÉGAS, P. R. A.; SILVA, T. L.; SOUZA, R. M.; BARBOSA, L.; VIÉGA, S. R. A.; BARRETTO, M. C. V.; MELO, A. S. Alterações em atributos químicos de solo cultivado com cana-de-açúcar e adição de vinhaça. Pesquisa Agropecuária Tropical, Goiânia, v. 40, n. 3, p.341-346, 2010.

BASSO, C. J.; SANTI, A. L.; LAMEGO, F. P.; SOMAVILLA, L.; BRIGO, T. J. Vinhaça como fonte de potássio: resposta da sucessão aveia-preta/milho silagem/milho safrinha e alterações químicas do solo na Região Noroeste do Rio Grande do Sul. Ciência Rural, Santa Maria, v. 43, n. 4, p.596-602, 2013.

BRZEZINSKI, C. R.; ABATI, J.; GELLER, A.; WERNER, F.; ZUCARELI, C. Produção de cultivares de alface americana sob dois sistemas de cultivo. Revista Ceres, Viçosa, MG, v. 64, n. 1, p.83-89, 2012.

CAVAllaRO JÚNIOR, M. L., TRANI, P. E., PASSOS, F. A., KUHN NETO, J., TIVELLI, S. W. Produtividade de rúcula e tomate em função da adubação (N e P) orgânica e mineral. Horticultura Brasileira, Brasília, v. 27, n. 2, p.S2265-S2272, 2009. 
COSTA, C. C.; CECÍlio FILHO, A. B.; REZENDE, B. L. A.; BARBOSA, J. C.; GRANGEIRO, L. C. Viabilidade agronômica do consórcio de alface e rúcula, em duas épocas de cultivo. Horticultura Brasileira, Brasília, v. 25, n. 3, p.34-040, 2007.

COSTA, C. M. F.; SEABRA JÚNIOR, S.; ARRUDA, G. R.; SOUZA, S. B. S. Desempenho de cultivares de rúcula sob telas de sombreamento e campo aberto. Semina: Ciências Agrárias, Londrina, v. 32, n. 1, p.93-102, 2011.

DAlRI, A. B., CARVAlHO NETO, O. F., MAZZONETTO, F., CORBANI, R. Z. Fertirrigação com vinhaça concentrada no desenvolvimento da alface. Revista Agrogeoambiental, Pouso Alegre, v. 6, n. 2, p.93-100, 2014.

EMPRESA BRASILEIRA DE PESQUISA AGROPECUÁRIA - EMBRAPA. Sistema Brasileiro de Classificação de Solos. v. 3. Brasília: UFV, 2013. 353 p.

ESPAÑA-GAMBOA, E.; MIJANGOS-CORTÉS, J. O.; HERNÁNDEZ-ZÁRATE, G.; MALDONADO, J. A. D.; ALZATE-GAVIRIA, L. M. Methane production by treating vinasses from hydrous ethanol using a modified UASB reactor. Biotechnology for Biofuels, [s. l.], v. 5, n. 1, p.82, 2012.

FAGERIA, N. K.; MOREIRA, A. The role of mineral nutrition on root growth of crop plants. Advances in Agronomy, San Diego, v. 110, n. 1, p.251-331, 2011

FERREIRA, D. F. Sisvar: a computer statistical analysis system. Ciência e Agrotecnologia, Lavras, v. 35, n. 6, p.1039-1042, 2011.

FIGUEIREDO, J. A. S.; INAGAKI, A. M.; SEABRA JÚNIOR, S.; SILVA, M. B.; DIAMANTE, M. S.; AQUINO, C. R. Cultivo de rúcula sob diferentes telados e campo aberto em conduções de alta temperatura e pluviosidade. Horticultura Brasileira, Brasília, v. 30, n. 1, p.S321-S327, 2012

FILGUEIRA, F. A. R. Novo manual de olericultura: agrotecnologia moderna na produção e comercialização de hortaliças. Viçosa: UFV, 2008. 421 p.

FIRMINO, M. C., FARIAS, M. S. S, MEDEIROS, S. S., GUERRA, H. O. C., GUIMARÃES, J. P. Altura e diâmetro do pinhão manso sob adubação fosfatada e uso de água residuária. ACSA - Agropecuária Científica no Semi-Árido, [s. l.], v. 11, n. 2, p.22-31, 2015.

FURlani, C. E. A.; GAMERO, C. A.; LEVIEN, R.; SIlvA, R. P.; CORTEZ, J. W. Temperatura do solo em função do preparo do solo e do manejo da cobertura de inverno. Revista Brasileira de Ciências do Solo, Viçosa, MG, v. 32, n. 1, p.375-380, 2008.

GARIGLIO, H. A. A.; MATOS, A.; MONACO, P. A. V. L. Alterações físicas e químicas em três solos que receberam doses crescentes de vinhaça. Irriga, Botucatu, v. 19, n. 1, p.14-24, 2014.

GOLCHIN, A.; VATANI, A.; SALVAND, B.; RAKHSH, F. The effects of application vinasseand additive nitrogen and phosphorus on growth and yield of tomato. Directory of Open Access Journals, [s. l.], v. 30, n. 1, p.11-18, 2017.

GUSMÃO, S. A. L.; LOPES, P. R. A.; SILVESTRE, W. V. D.; OLIVEIRA NETO, C. F.; PEGADO, D. S.; SILVA, C. L. P.; SANTOS, L. F. S.; FERREIRA, S. G. Cultivo de rúcula 
nas condições do Trópico Úmido em Belém. Horticultura Brasileira, Brasília, v. 21, n. 2, p.30, 2003.

HELDT, H. W.; PIECHULLA, B. Phloem transport distributes photoassimilates to the various sites of consumption and storage. In: Plant Biochemistry. v. 4. San Diego: Academic, 2011. Cap. 13, p. 337-348.

INSTITUTO NACIONAL DE METEOROLOGIA - INMET. Banco de Dados Meteorológicos para Ensino e Pesquisa - BDMEP. Brasília, 2018. Disponível em: http://www.inmet.gov.br/projetos/rede/pesquisa/. Acesso em: 20 abr. 2018.

JESUS, E. G.; FATIMA, R. T.; GUERRERO, A. C.; ARAÚJO, J. L.; BRITO, M, E, B. Growth and gas exchanges of arugula plants under silicon fertilization and water restriction. R. Bras. Eng. Agríc. Ambiental, Campina Grande, v. 22, n. 2, p.119-124, 2018.

KERBAUY, G. B. Fisiologia vegetal. Rio de Janeiro: Guanabara Koogan, 2009. 452 p.

LIMA NETO, A. J.; DANTAS, G. T. A.; CAVAlCANTE, F. L.; DIAS, J. T.; DINIZ, A. A. Biofertilizante bovino, cobertura morta e revestimento lateral dos sulcos na produção de pimentão. Revista Caatinga, Mossoró, v. 26, n. 3, p.1-8, 2013.

MARENCO, R. A.; LOPES, N. F. Fisiologia vegetal: fotossíntese, respiração, relações hídricas e nutrição mineral. 3. ed. Viçosa, MG: UFV, 2009. 486 p.

MARQUES, T. A.; PINTO, L. E. V. Energia da biomassa de cana-de-açúcar sob influência de hidrogel, cobertura vegetal e profundidade de plantio. Revista Brasileira de Engenharia Agrícola e Ambiental, Campina Grande, v. 17, n. 6, p.680-685, 2013.

MARTORANO, L. G.; BERGAMASCHI, H.; DALMAGO, G. A.; FARIA, R. T.; MIELNICZUK, J.; COMIRAN, F. Indicadores da condição hídrica do solo com soja em plantio direto e preparo convencional. Revista Brasileira de Engenharia Agrícola e Ambiental, Campina Grande, v. 13, n. 4, p.397-405, 2009.

MEllo, G. A. B.; CARVAlhO, D. F.; MEDICI, L. O.; SILVA, A. C.; GOMES, D. P., PINTO, M. F. Organic cultivation of onion under castor cake fertilization and irrigation depths. Acta Scientiarum Agronomy, Maringá, v. 40, n. 1, p.34-42, 2018.

MONTEIRO NETO, J. L. L.; SILVA, A. C. D.; SAKAZAKI, R. T.; TRASSATO, L. B.; ARAÚJO, W. F. Tipos de coberturas de solo no cultivo de alface (Lactuca sativa L.) sob as condições climáticas de Boa Vista, Roraima. Boletim do Museu Integrado de Roraima, Roraima, v. 8, n. 2, p.47-52, 2014.

NEGRINI, A. C. A. Desempenho de alface (Lactuca sativa $L$ ) consorciada com diferentes adubos verdes. 2007. 113 f. Dissertação (Mestrado em Fitotecnia) - Universidade de São Paulo - Escola Superior de agricultura Luiz de Queiroz, Piracicaba, 2007

OLIVEIRA, A. D.; MEIRELleS, M. L.; FRANCO, A. C. Variáveis meteorológicas e estimativas da evapotranspiração num cultivo de soja no Cerrado. Planaltina: EMBRAPA, 2011. 21 p. (Boletim técnico, 302). 
OLIVEIRA, E. Q.; SOUZA, R. J.; CRUZ, M. C. M.; MARQUES, V. B.; FRANÇA, A. C. Produtividade de alface e rúcula, em sistema consorciado, sob adubação orgânica e mineral. Horticultura Brasileira, Brasília, v. 28, n. 1, p.36-40, 2010.

OLIVEIRA, L. A. A.; BEZERRA NETO, F.; SILVA, M. L.; OLIVEIRA, O. F. N.; LIMA, J. S. S.; BARROS JÚNIOR, A. P. Viabilidade agronômica de policultivos de rúcula/cenoura/alface sob quantidades de flor-de-seda e densidades populacionais. Revista Caatinga, Mossoró, v. 28, n. 4, p.116, 2015.

OLIVEIRA, W. S.; BRITO, M. E. B.; ALVES, R. A. B.; SOUZA, A. S.; SILVA, E. G. Cultivo da cana-de-açúcar sob fertirrigação com vinhaça e adubação mineral. Revista Verde, [s.l.], v. 9, n. 1, p.1-5, 2014.

PALARETTI, L. F.; DALRI, A. B.; DANTAS, G. F.; FARIA, R. T.; SANTOS, W. F.; SANTOS, M. G. Produtividade do manjericão (ocimum basilicum L.) fertirrigado utilizando vinhaça concentrada. Revista Brasileira de Agricultura Irrigada, [s. l.], v. 9, n. 5, p.326334, 2015.

PEIXOTO, C. P.; CRUZ, T. V.; PEIXOTO, M. F. S. P. Análise quantitativa do crescimento de plantas: Conceitos e Prática. Enciclopédia Biosfera, [s. l.], v. 7, n. 13, p.51-76, 2011.

PIMENTEL, M. S.; TOGUN, A. O.; GUERRA, J. G. M.; DE-POLLI, H. Performance of roquette crop fertilized with cattle and green manure using two planting densities. Revista Brasileira de Agroecologia, [s. l.], v. 5, n. 2, p.139-148, 2010.

PORTO, R. A.; BONFIM-SILVA, E. M.; SOUZA, D. S. M.; CORDOVA, N. R. M.; POLYZEL, A. C.; SILVA, T. J. A. Adubação potássica em plantas de rúcula: produção e eficiência no uso da água. Revista Agro@mbiente, [s. l.], v. 7, n. 1, p.28-35, 2013.

RESENDE, F. V.; SOUZA, L. S.; OLIVEIRA, P. S. R.; GUALBERTO, R. Uso de cobertura morta vegetal no controle da umidade e temperatura do solo, na incidência de plantas invasoras e na produção da cenoura em cultivo de verão. Ciência Agrotecnologia, [s. l.], v. 2, n. 9, p.100-105, 2005.

SÁ, G. D.; REGHIN, M. Y. Desempenho de duas cultivares de chicória em três ambientes de cultivo. Ciência e Agrotecnologia, Lavras, v. 32, n. 2, p.378-384. 2008.

SANTOS, J. D. Utilização da vinhaça como componente de solução nutritiva para hidroponia. 2010. 75 f. Dissertação de (Mestrado em Processos Biotecnológicos) Universidade Federal do Paraná, Curitiba, 2010a.

SANTOS, R. S. S. Cultivo da rúcula em fibra de côco com solução nutritiva salinizadas em diferentes épocas. 2010. 76 f. Dissertação (Mestrado em Irrigação e Drenagem) Universidade Federal Rural do Semi-Árido, Mossoró, 2010b.

SILVA, A. V. L. Uso de manipueira como biofertilizante na cultura da rúcula (Eruca sativa Miller) cultivada em estufa. 2010. 40 f. Trabalho de Conclusão de Curso (Graduação em Agronomia) - Universidade Federal de Alagoas, Rio Largo, 2010. 
SILVA, J. K. M.; OLIVEIRA, F. A.; MARACAJÁ, P. B.; FREITAS, R. S.; MESQUITA, L. $\mathrm{X}$. Efeito da salinidade e adubos orgânicos no desenvolvimento da rúcula. Caatinga, Mossoró, v. 21, n. 5, p.30-35, 2008.

SILVA, M. C. L.; MELO, P. C. S.; LIMA, L. E.; GONÇALVES, M. F. Horta em todo canto. Pernambuco: Caisanpe, 2018. 32 p.

SOLINO, A. J. S.; FERREIRA, R. O.; FERREIRA, R. L. F.; ARAÚJO NETO, S. E.; NEGREIRO, J. R. S. Cultivo orgânico de rúcula em plantio direto sob diferentes tipos de coberturas e doses de composto. Revista Caatinga, Mossoró, v. 23, n. 2, p.18-24, 2010.

SUGASTI, J. B. Consorciação de hortaliças e sua influência na produtividade e ocorrência de plantas espontâneas e artrópodes associados. 2012. 158 f. Dissertação (Mestrado em Agronomia) - Universidade de Brasília, Brasília, 2012.

UENO, C. R., COSTA, A. C. S., GIMENES, M. L., ZANIN, G. M. Cultivo de alface com vinhaça submetida à biodigestão. In: ENCONTRO INTERNACIONAL DE PRODUÇÃO CIENTÍFICA CESUMAR, 2013, Maringá. Anais [...] Maringá: UNICESUMAR, 2013. p. 510.

UENO, C. R. J.; COSTA, A. C. S.; GIMENES, M. L.; ZANIN, G. M. Agricultural recycling of biodigested vinasse for lettuce production. Revista Ambiente \& Água. [s. l.], v. 9, n. 4, p.593-601, 2014.

TAIZ, L.; ZEIGER, E. Fisiologia vegetal. 5. ed. Porto Alegre: Artemed, 2013. 954 p.

TAIZ, L.; ZEIGER, E.; MOLLER, I.; MURPHY, A. Fisiologia e desenvolvimento vegetal. 6. ed. Porto Alegre: Artmed, 2017. 888 p.

TEIXEIRA, C. M.; CARVAlHO, G. J.; ANDRADE, M. J. B. A.; SILVA, C. A.; PEREIRA, J. M. Decomposição e liberação de nutrientes das palhadas de milheto e milheto + crotalária no plantio direto do feijoeiro. Acta Scientiarum Agronomy, Maringá, v. 31, n. 4, p.647-653, 2009.

TRANI, P. E.; FORNASIER, J. B.; LISBÃO, R. S. Cultura da rúcula. Campinas, IAC, 1992. $15 \mathrm{p}$. 